\title{
Fasciolosis: grading the histopathological lesions in naturally infected bovine liver in Mosul city
}

\author{
S.S. Al-Mahmood ${ }^{1 *}$ and H.B. Al-Sabaawy ${ }^{2}$ \\ ${ }^{1}$ Department of Pathology and Poultry Diseases, College of Veterinary Medicine, University of Mosul, Mosul, ${ }^{2}$ Department of \\ Pathology and Poultry Diseases, College of Veterinary Medicine, University of Tikrit, Tikrit, Iraq, "saevan981@ yahoo.com
}

(Received October 18, 2018; Accepted March 31, 2019)

\begin{abstract}
Fasciolosis cause economic losses in cattle that breed in Iraq and the world. About $4 \%$ of bovine liver's samples included in the current study exhibited classical pathological lesions of fasciolosis. Samples of cattle livers infected with fasciolosis were taken for histopathology. Eighteen grading criteria with four scoring level have been chosen to grading the microscopic lesions caused by Fasciola hepatica into a mild infection (grade I), moderate infection (grade II) and severe infection (grade III). The type of hepatic degeneration or necrosis, cloudy cell swelling, coagulative necrosis, infiltration of inflammatory cells, with patterns of infiltration, also type of infiltrated cells, fibrosis between hepatic cells or in portal area, affection to hepatic cords arrangement, hepatic sinusoids, extensions of hemorrhage, pigment deposition, hyperplasia of bile duct, thickness of hepatic capsule and presence of liver fluke were the main grading levels. In grade, I the microscopic lesions were characterized by simple or mild in their nature with very good reversible prognosis, while grade II characterized by moderate severity of the lesions with a good reversible prognosis, while grade III characterized by hostile severity with bad irreversible prognosis as a result of architecture changes in liver histology. In conclusion, we believed that this grading system could be used as a guide when examining histopathological liver's samples infected with $F$. hepatica to identify the stage of infection and proposed an accurate prognosis.
\end{abstract}

Keywords: Fasciolosis, Grading system, Pathological lesions, Bovine, Liver Available online at http://www.vetmedmosul.com

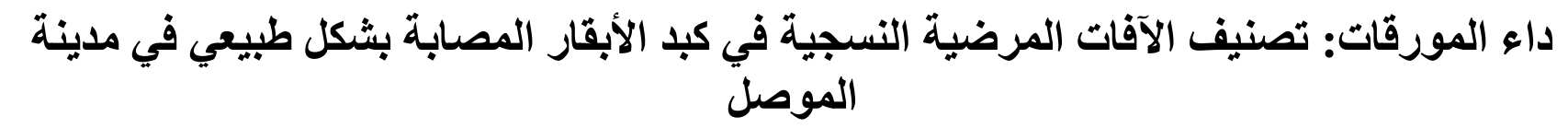

سيقان سعد فاضل المحمود' وهديل باسم ذنون السبعاوي

' فرع الأمر اض وأمر اض الدواجن، كلية الطب البيطري، جامعة الموصل، الموصل، ^ فرع الأمر اض وأمر اض الدواجن، كلية الطب

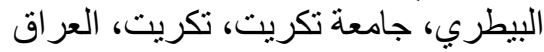

الخلاصة

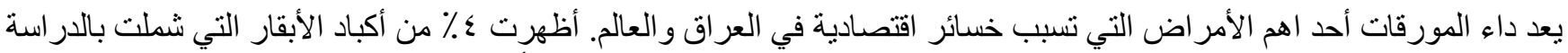

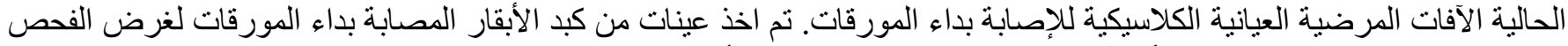

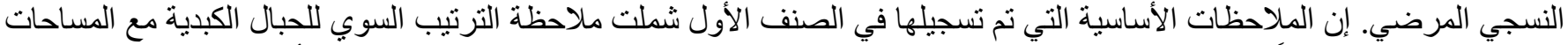

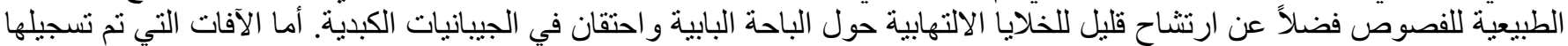

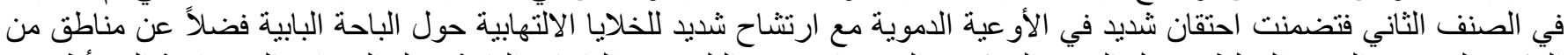

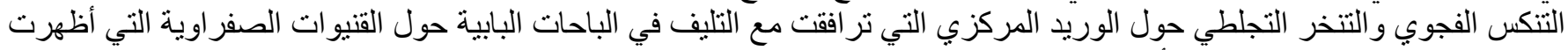

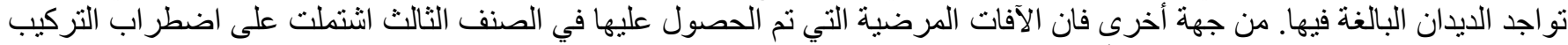

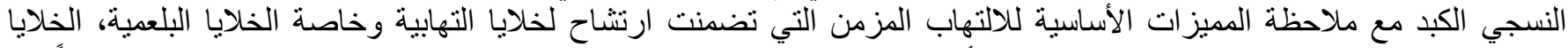

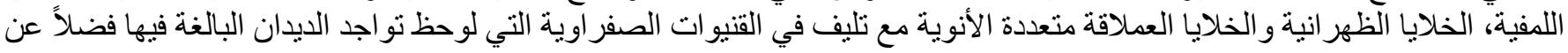




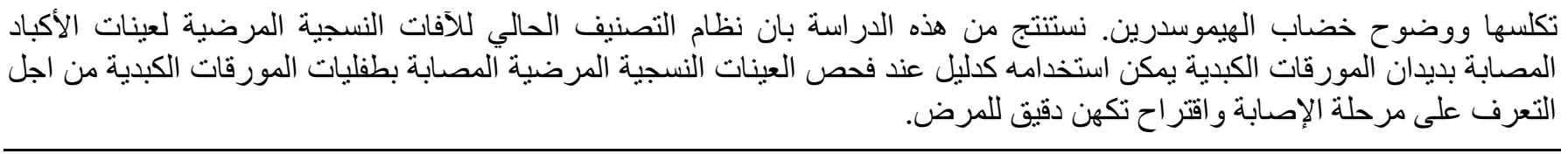

\section{Introduction}

Fasciolosis is a chronic disease that affects many hosts include farm animals especially cattle, these parasites cause a wasting disease in cattle with fetal prognosis (1). It is caused by infection with two main pathogenic species which either Fasciola hepatica or Fasciola gigantica, they both belong to genus Fascial of family Fasciolidae of order Plagiorchiida of phylum Platyhelminthes of kingdom Animalia (2). All mammals are susceptible to infection with these parasites; however, this condition causes significant liver dysfunction in cattle (3). The life cycle starts when infected final hosts shed the eggs that contain one miracidium with feces to environment, the miracidium release from egg to infect a lymnaeid snail which considers as intermediated host, these miracidium develop to cercaria inside snail body to be shed later on grass to develop into metacercaria under the effect of rainfall, metacercaria consider the infective stage to final hosts (cattle) through ingestion, later metacercaria exocyst in duodenum to invade intestinal wall then reach liver and biliary ducts, where they grow up to an adult worm, after few weeks of development the adult worms release eggs with feces to environment (4). The persistence of adult worm in the biliary system will cause continuous irritation that results in an inflammatory reaction of chronic features (5). This chronic inflammation characterizes by infiltration of inflammatory cells especially macrophages and lymphocytes with few numbers of eosinophils, hyperplasia of fibrocytes causing fibrosis around portal areas, with metaplasia and fibrosis of bile cuniculi (6). There have been many recent pathological studies in Iraq and other countries which focus on lesions caused by Fasciola spp in the liver of cattle, sheep, and goat $(7,8)$. However, no histopathological study focuses on the gradual development of these lesions step by step, therefore; the purpose of current study was to fully report the development of histopathological lesions caused by these parasites by grading histopathological lesions into three different grades in order to give the exact diagnosis and accurate prognosis.

\section{Materials and methods}

\section{Liver samples}

A total of 425 samples of liver were have been exanimated. These liver samples of cattle have been slaughtered at local butcher shops in Mosul city. The liver samples that showed gross lesions of fasciolosis with the presence of liver fluke in hepatic tissue, have been fully grossed with represented samples have been taken for histopathological examination.

\section{Collection of samples and histopathology}

A random ten tissue samples were taken from each liver sample in the dimension of $1 \mathrm{~cm}^{3}$ from the area showed gross lesions with emphasizing on the area of bile ducts. Later, these samples fixed in neutral buffered formalin $10 \%$, dehydrated by alcohol, later cleared by xylol, then embedded in paraffin wax (9). The histological paraffine blocks sliced at five micrometers by rotary microtome, stained by routine Harris hematoxylin and alcoholic Eosin stain (HE) (9). A Periodic acid Schiff's reagent stain (PAS) were used to the better illustration of histopathological lesions (9).

\section{Grading levels of liver lesions (10)}

Grade I: Simple inflammatory reaction with periportal or interstitial infiltration of inflammatory cells. Grade II: Significant inflammatory reaction, telangiectasia, congestion of central vein, degenerative or necrotic changes in hepatocytes, with the presence of the parasite in the biliary system. Grade III: Chronic inflammatory reaction, with centrilobular degenerative and necrotic changes, hyperplasia of fibrocytes in a portal area with metaplasia and distension of bile cuniculi that contained Fasciola spp. in their lumen (Table 1).

\section{Scoring levels of liver grades}

A scoring system has been invented depends on histopathological lesions associated with infection by Fasciola spp, the presence of mild lesions was included in grade I will moderate histopathological changes where classifies under grade II, while the severely expressed lesions included in grade III (11). The protocol for examination of histopathological slides are as describe by Corley et al. (11), A ten random field from a monitoring site in each slide was examined under the light of microscopy at 40x, 100x, 400, and 1000x magnification power. The site of monitoring is (a) the area around the central vein, and (b) portal and periportal area. Calculation the number of cells that showed each lesion mentioned in table 1. A mean of each lesion that has been recorded into the previous step. Depended upon the mean of each lesion that has been recorded, the three grades own their specific criteria to be classified slides under each grade. 
Table 1: Explain the criteria used in different grading level

\begin{tabular}{lccc}
\hline \multirow{2}{*}{ Histopathological lesions } & \multicolumn{3}{c}{ Grading Criteria } \\
\cline { 2 - 4 } & I & II & III \\
\hline Cloudy cell swelling & $1-10$ & $11-30$ & $<30$ \\
Vacuolar degeneration & $1-10$ & $11-30$ & $<30$ \\
Fatty degeneration & $1-5$ & $6-15$ & $<10$ \\
Liquefactive necrotic cell & $1-5$ & $6-10$ & $<10$ \\
Coagulative necrotic cell & $1-5$ & $6-10$ & $<30$ \\
Macrophages infiltration & $1-10$ & $11-30$ & $<30$ \\
Neutrophils infiltration & $1-10$ & $11-30$ & $<30$ \\
Lymphocytes infiltration & $1-10$ & $11-30$ & $<1$ \\
Giant cell infiltration & 0 & 1 & +++ \\
Interstitial hepatic fibrosis & + & ++ & +++ \\
Hepatic cords arrangement & + & ++ & $<10$ \\
Congested hepatic sinusoids & $1-5$ & $6-10$ & +++ \\
Hepatic hemorrhage & + & ++ & $<10$ \\
Hemosiderin pigmentation & $1-5$ & $6-10$ & +++ \\
Portal fibrosis & + & ++ & +++ \\
Periportal infiltration & + & ++ & +++ \\
Bile duct hyperplasia & + & $3-5$ & $<5$ \\
Presence of liver fluke & $1-2$ & good prognosis & bad prognosis \\
\hline Prognosis & very good prognosis & reversible disease & irreversible disease \\
\hline
\end{tabular}

\section{Results}

\section{Prevalence of fasciolosis}

The result of the current study showed that the prevalence of infection with liver fluke was $4 \%$ (17/425) (Table 2).

Table 2: Showed the analysis of cattle's liver exhibiting different grading level

\begin{tabular}{lcc}
\hline Grade Level & \% infection & No. of infection \\
\hline Grade I & $0.71 \%$ & 3 \\
Grade II & $1.18 \%$ & 5 \\
Grade III & $2.11 \%$ & 9 \\
\hline Total & $4.00 \%$ & 17 \\
\hline
\end{tabular}

\section{Histopathological Grading \\ Grade I}

About $0.71 \%(3 / 425)$ of cattle's liver showed the criteria of this grade. Histopathological lesions of liver tissue showed normal hepatic cord arrangement and normal hepatic lobulation areas (Figure 1), with few infiltrations of inflammatory cells especially macrophages (Figure 2) around the portal area (Figure 3), which associated with congestion in less notifiable hepatic sinusoids (Figure 4).

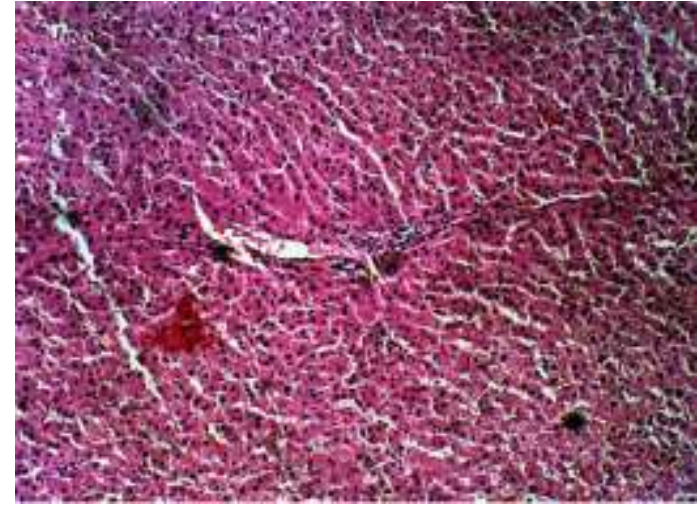

Figure 1: Grade I histological section of cattle's liver infected with Fasciola spp, showed normal hepatic cord arrangement and normal hepatic lobulation areas. HE. 100X.

\section{Grade II}

In this grading level, about $1.18 \%(5 / 425)$ of liver samples showed the criteria of this grade. The histopathological lesions composed from severely congested blood vessels in portal area (Figure 5) and central vein associated with telangiectasias (Figure 6), huge number of periportal infiltration of inflammatory cells especially macrophages and lymphocytes (Figure 7), areas of vacuolar degeneration and coagulative necrosis around central vein (Figure 8), with fibrosis in portal areas (Figure 
9). An adult liver fluke in the bile duct was identified which results in hyperplasia of bile ducts showed a finger-like projection into lumen leads to stoppage of bile pigment flow (Figure 10).

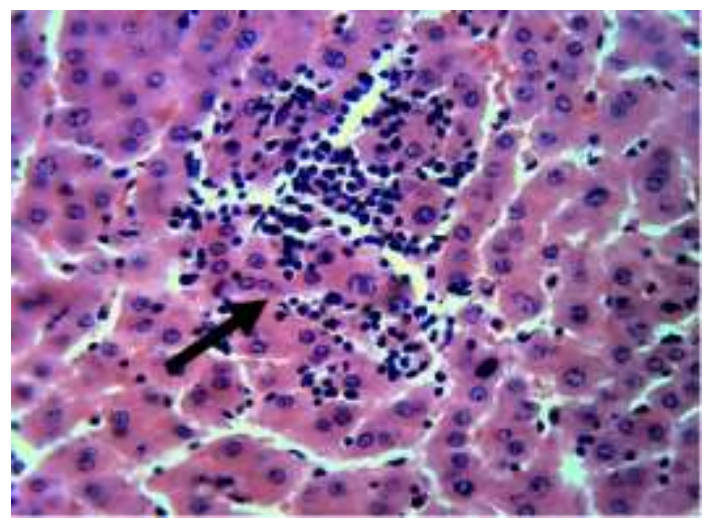

Figure 2: Grade I histological section of cattle's liver infected with Fasciola spp, showed focal infiltrations of inflammatory cells especially macrophages (arrow). HE. 400X.

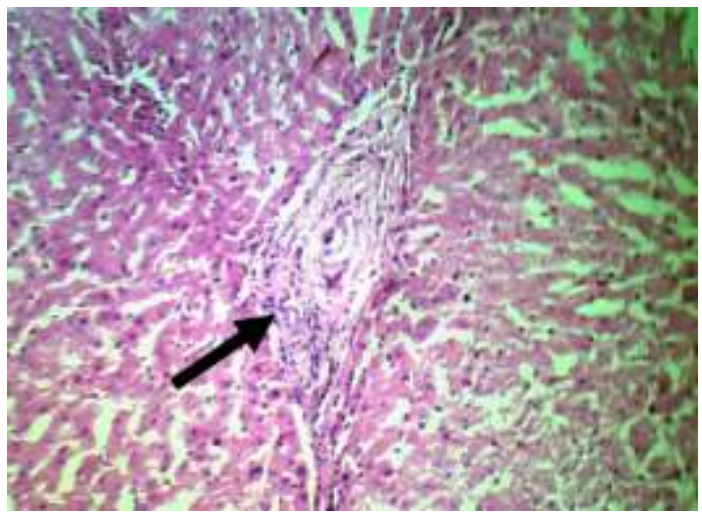

Figure 3: Grade I histological section of cattle's liver infected with Fasciola spp, showed infiltration of the inflammatory cell around the portal area (arrow). HE. $100 \mathrm{X}$.

\section{Grade III}

In this advance grading level, about $2.11 \%(9 / 425)$ samples showed the criteria of this grade. The normal architecture of liver histology is disrupted, and the normal arrangement of hepatic cord were absent (Figure 11), these lesions associated with observation of classical features of chronic inflammation in affected samples (Figure 12), these lesions were centrilobular and periportal infiltration of inflammatory cells especially macrophages, lymphocytes (Figure 13), epithelioid cells (Figure 14) and giant cells (Figure 15), with less extent of neutrophils, these infiltrations associated with centrilobular massive coagulative necrotic hepatocytes with less appearance of vacuolar degeneration (Figure 16). All these lesions associated with hyperplasia of fibrocytes that cause lobulation of hepatic cells with special emphasizing of occurrence around the affected portal area to form a fibrous connective tissue (Figure 17), also the affected bile duct showed hyperplasia of epithelial cell as figure like projection with metaplasia of columnar epithelial cells to cuboidal or squamous epithelial cells (Figure 18). The lumen of affected bile duct contained an adult form of Fasciola spp (Figure 19), these lesions recorded in association with calcification of biliary system due to calcium salt deposition in these severely affected areas (Figure 20), with hemosiderin pigmentation (Figures 21 and 22).

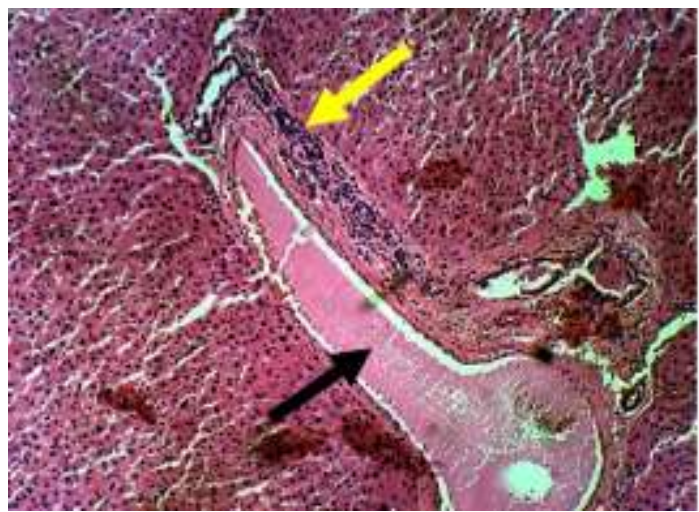

Figure 4: Grade I histological section of cattle's liver infected with Fasciola spp, showed congestion in liver blood vessels at the portal area (arrow) with infiltration of inflammatory cells (arrow). HE. 100X.

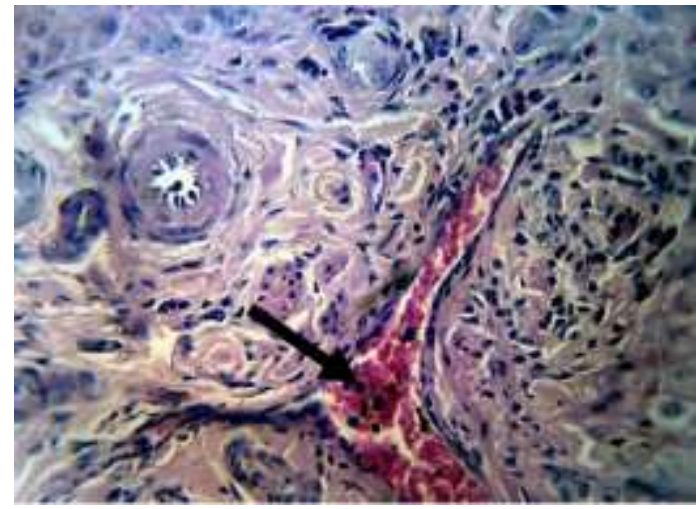

Figure 5: Grade II histological section of cattle's liver infected with Fasciola spp, showed severely congested blood vessels in the portal area (arrow). HE. 400X. 


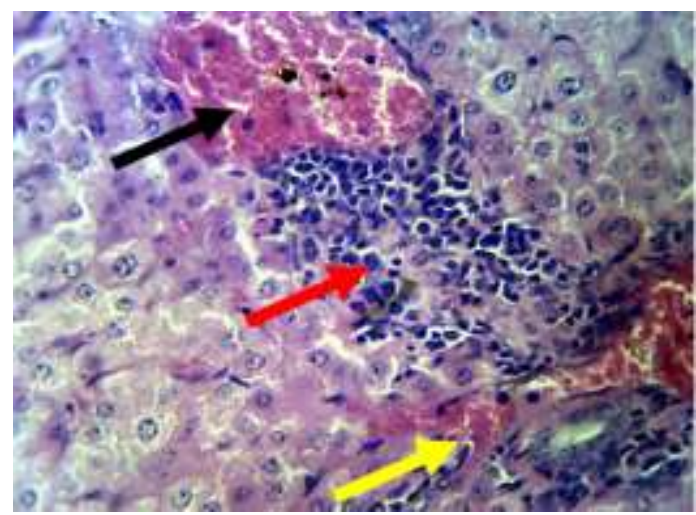

Figure 6: Grade II histological section of cattle's liver infected with Fasciola spp, showed congestion of central vein (arrow), telangiectasias (arrow), and infiltration of inflammatory cells (arrow). HE. 400X.

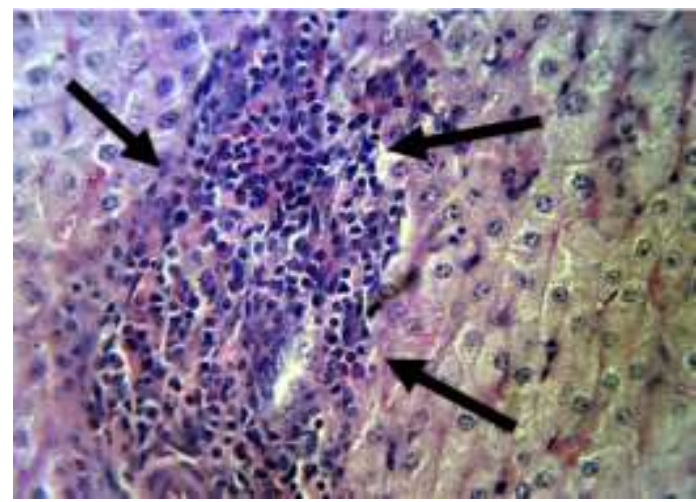

Figure 7: Grade II histological section of cattle's liver infected with Fasciola spp, showed a huge number of periportal infiltration of inflammatory cells especially macrophages and lymphocytes (arrows). HE. 400X.

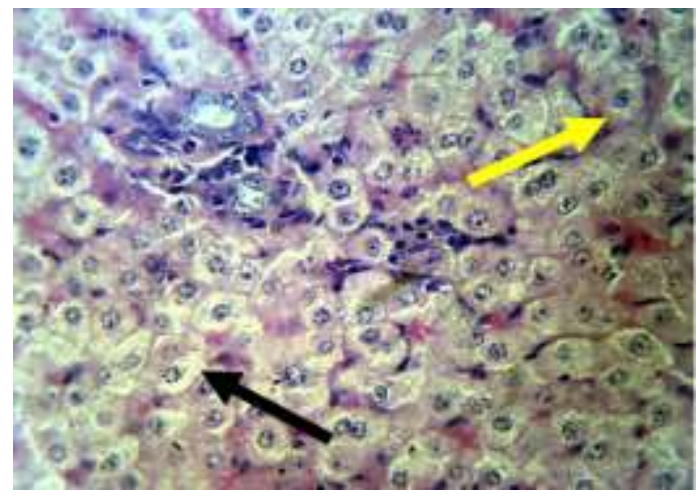

Figure 8: Grade II histological section of cattle's liver infected with Fasciola spp, showed the area of vacuolar degeneration (arrow) with coagulative necrosis (arrow). HE. 400X.

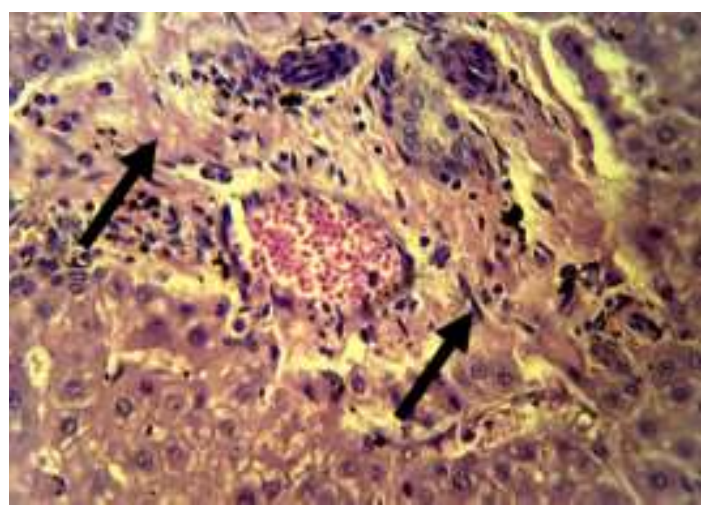

Figure 9: Grade II histological section of cattle's liver infected with Fasciola spp, showed fibrosis in portal areas (arrows). HE. 400X.

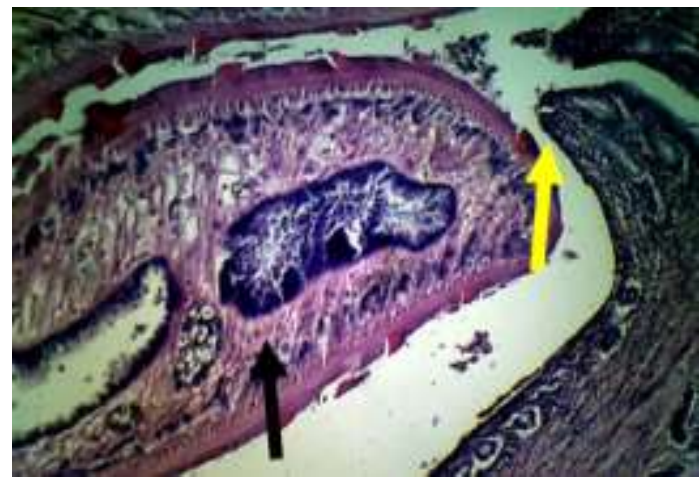

Figure 10: Grade II histological section of cattle's liver infected with Fasciola spp, showed the presence of adult liver fluke worms in the bile duct (arrow), causing hyperplasia of bile ducts in finger-like projections (arrow). PAS. 100X.

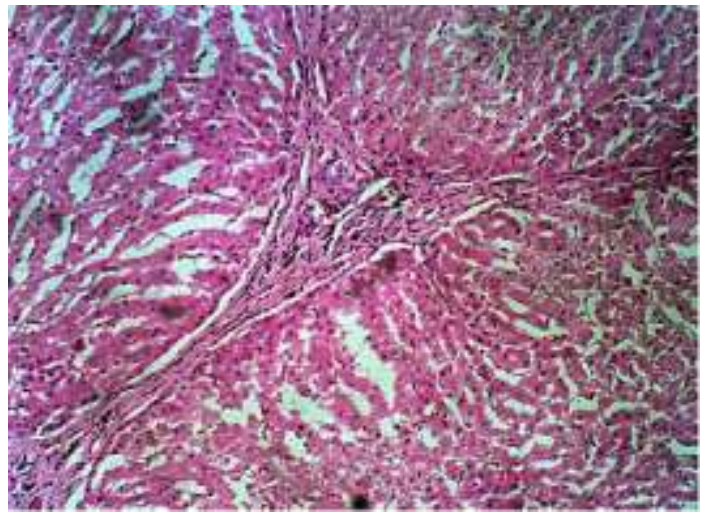

Figure 11: Grade III histological section of cattle's liver infected with Fasciola spp, showed the absence of normal liver histology. HE. 100X. 


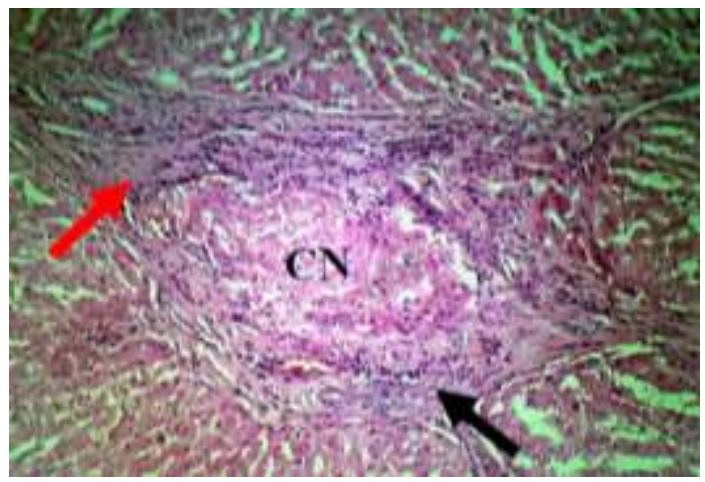

Figure 12: Grade III histological section of cattle's liver infected with Fasciola spp, showed classical features of chronic inflammation recorded in affected samples included coagulative necrosis $(\mathrm{CN})$, infiltration of inflammatory cells (arrow) and fibrosis (arrow). HE. 100X.

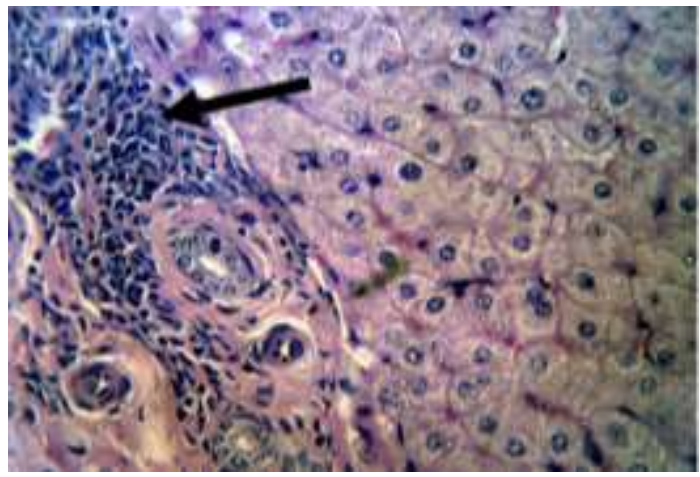

Figure 13: Grade III histological section of cattle's liver infected with Fasciola spp, showed periportal infiltration of inflammatory cells especially macrophages and lymphocytes (arrow), with portal fibrosis (arrow). HE. 400X.

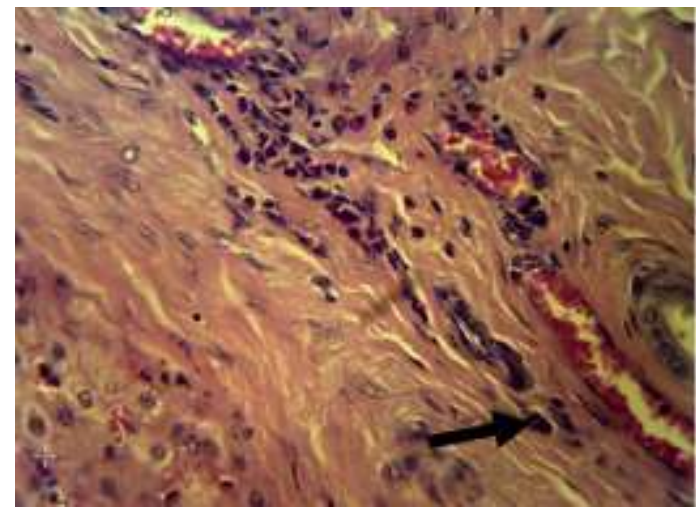

Figure 14: Grade III histological section of cattle's liver infected with Fasciola spp, showed epithelioid cell (arrow). HE. 400X.

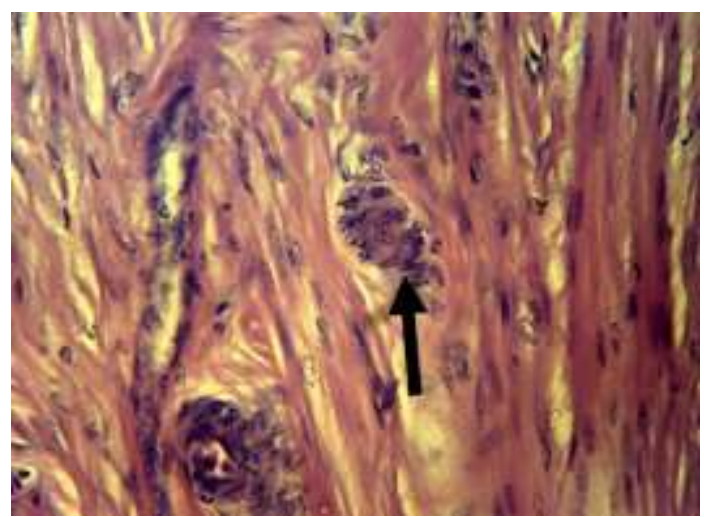

Figure 15: Grade III histological section of cattle's liver infected with Fasciola spp, showed multinucleated giant cell (arrow). HE. 1000X.

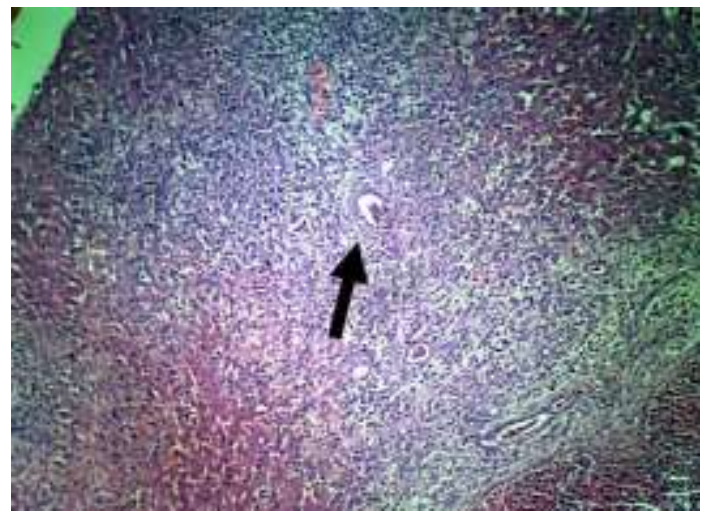

Figure 16: Grade III histological section of cattle's liver infected with Fasciola spp, showed centrilobular massive coagulative necrotic hepatocytes (arrow). HE. 100X.

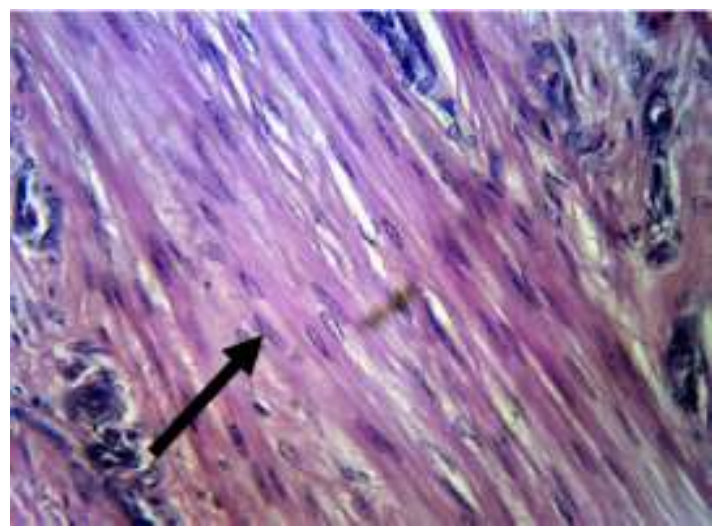

Figure 17: Grade III histological section of cattle's liver infected with Fasciola spp, showed hyperplasia of fibrocytes (arrow). HE. 400X. 


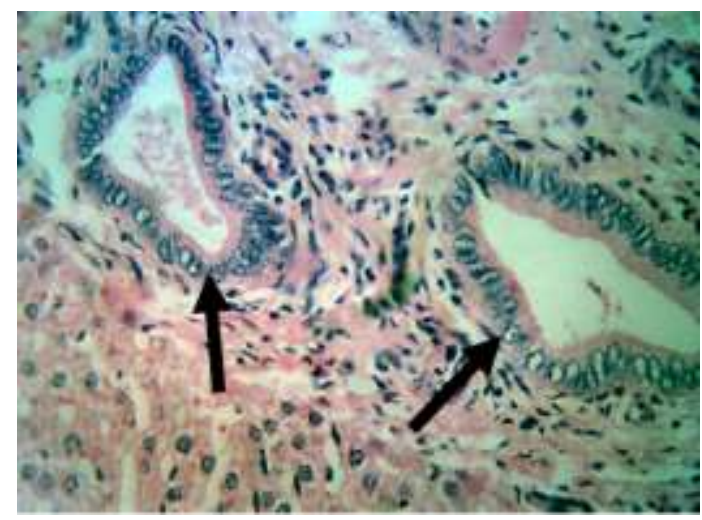

Figure 18: Grade III histological section of cattle's liver infected with Fasciola spp, showed metaplasia of columnar epithelial cells to cuboidal epithelial cells (arrows). HE. $400 X$.

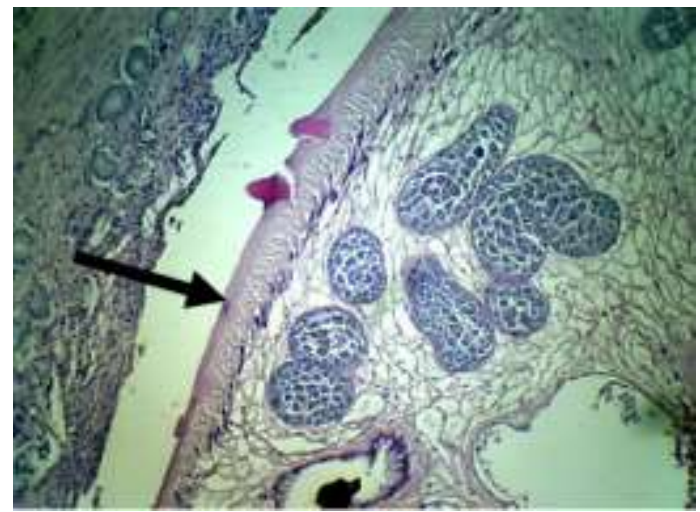

Figure 19: Grade III histological section of cattle's liver infected with Fasciola spp, showed an adult form of Fasciola spp in the bile duct (arrow). PAS. 100X.

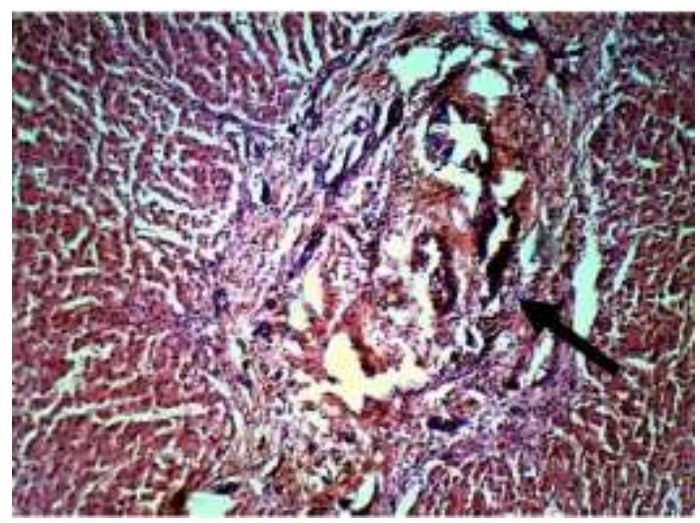

Figure 20: Grade III histological section of cattle's liver infected with Fasciola spp, showed calcification of bile duct (arrow). HE. 100X.

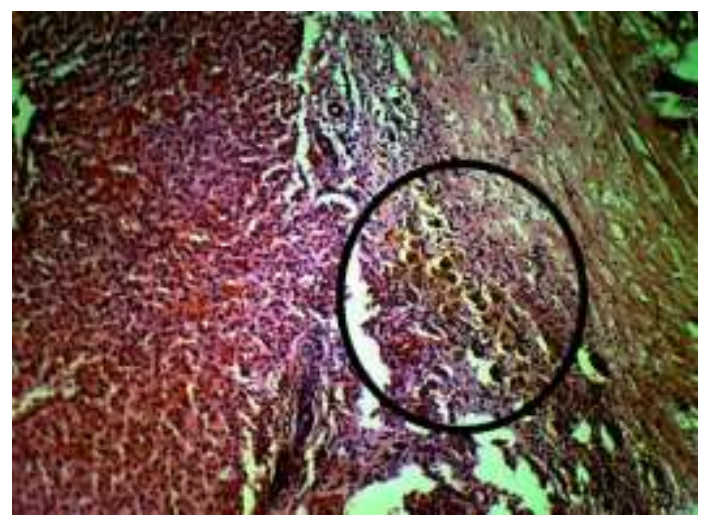

Figure 21: Grade III histological section of cattle's liver infected with Fasciola spp, showed hemosiderin pigmentation (circle). HE. 100X.

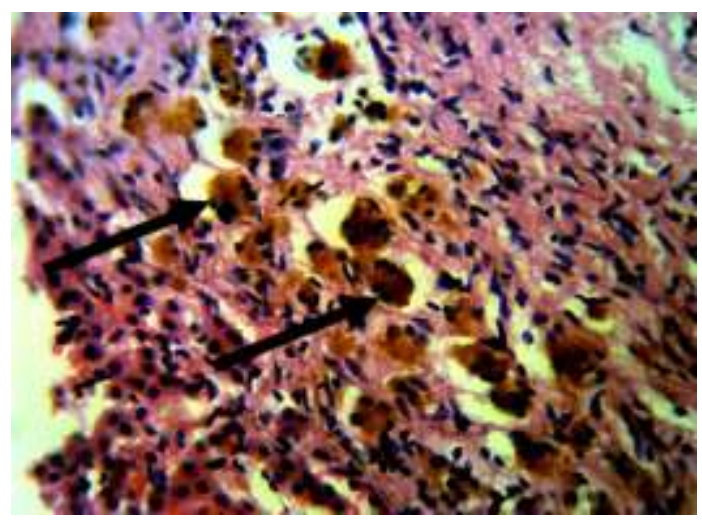

Figure 22: Grade III histological section of cattle's liver infected with Fasciola spp, showed hemosiderin pigmentation (arrow). HE. 400X.

\section{Discussion}

The result of the current study recorded $4 \%$ of Fasciola spp infection as prevalence percentage in cattle's liver, these results was extremely close to results obtained by AlMahmood et al. (7), were they recorded about $3.34 \%$ of fasciolosis, the convergence in these results occurred due to weather similarity in Mosul and Kirkuk city during the same seasons were both studies conducted. The climate conditions as humidity, temperature, and rainfall play a role in spread the infection especially on the maturation of eggs that shed from definitive and intermediate hosts (12). Another study done by Kadir et al. (13) recorded $1.27 \%$ and Kadir and Rasheed (14) recorded $2.63 \%$ of fasciolosis in ruminant, these results were less than that recorded in the current study, these differences can be explained due to weather changes also. Both studies conducted and recorded their result in summer months at Kirkuk province, in which 
high temperature will cause the destruction of eggs that shed from ruminant $(15,16)$.

In this study, we examined 425 livers, 17 liver's samples showed classical histopathological lesions of Fasciola spp infection, all other studies strongly implicated both Fasciola hepatica and Fasciola gigantica as the causative agent of this condition in cattle $(17,18)$.

The results showed that the most affected sites were portal area especially bile ducts, where the inflammatory reaction started then extended to other parts of hepatic tissue (19). Infiltration of inflammatory cells especially macrophages at first stages of infection occurs because of increased in releasing IL-4 alone or with IL-10, both cytokines cause attraction of lymphocytes to the site of chemotaxis in the second subsequent response of cell migration (17). The affected cells will increase the releasing of IL-13 that act as a trigger to T- helper ${ }^{2}$ lymphocytes to overcome the continuous irritation (20). With time the lesions caused by Fasciola spp were increased in severity, this occurs due to increase in the level of tumor growth factor - beta (TGF- $\beta$ ) which cause immunosuppression of host defenses to facilitate parasite colonization (21).

The features of acute inflammation in cases of Fasciola spp infection was not clearly observed, this explained when parasites induced a transit decrease in interferon - gamma (IFN- $\gamma$ ) level followed by down-regulation of cellular response, that cause increase in the number of macrophages than other cells, which promote the chronic inflammatory process (22). After that falling and dysregulation of defenses to overcome Fasciola spp infection associated with an increase in the level of IFN- $\gamma$ alone or with previously released IL-4 lead to the generation of the multinucleated giant cell to destroy the parasites (23). Hyperplasia of fibrocytes that seen in late stages of infection occurs as a result of chronic inflammatory reaction, the peripheral blood monocytes can differentiate into fibrocytes, this process occurs under the effect of both IL-4 and IL-13 which chemotactic these cells to site of infection then differentiate them into fibrocytes under the effect of TNF- $\alpha(24,25)$. The biliary obstruction and bile pigment secretion stasis occur due to the presence of adult worms in biliary system with deposition of calcium salt in wall of these ducts by processes known as calcification, these depositions occur under influence of TNF- $\alpha$ that trigger $\mathrm{Ca}^{+2}$ to be deposited as defense mechanism against prolonged irritation induced by adult liver fluke (26).

\section{Conclusion}

In conclusion, we believed that this grading system could be used as a guide when examining histopathological liver's samples to identify the stage of infection and proposed an accurate prognosis.

\section{Acknowledgement}

The Authors wish to express their appreciation and thanks to College of Veterinary Medicine, University of Mosul for supporting this study.

\section{References}

1. Beesley J, Caminade C, Charlier J, Flynn RJ, Hodgkinson JE, Martinez A, Martinez M, Perez J, Rinaldi L, Williams D. Fasciola and fasciolosis in ruminants in Europe: Identifying research needs. Transbound Emerg Dis. 2018;65(1):199-216. doi: 10.1111/tbed.12682

2. Shimalov VV, Shimalov VT. Findings of Fasciola hepatica (Linnaeus, 1758) in wild animals in Belorussian Polesie. Parasitol Res. 2000;86:527. doi: 10.1007/s004360050707

3. Mason C. An outbreak of fasciolosis with associated metabolic disease in a dairy herd. Res Vet Sci. 2002;72(1):33. doi: 10.1016/S0034-5288(02)90095-0

4. Taylor MA, Coop RL, Wall RL. Veterinary parasitology. $4^{\text {th }}$ ed. West Sussex: John Wiley and Sons; 2016. 352-435 p. doi: 10.1002/9781119073680

5. Mellau LSB, Nonga HE, Karimuribo ED. A slaughterhouse survey of liver lesions in slaughtered cattle sheep and goats at Arusha Tanzania. Res J Vet Sci. 2010;3:179-188. doi: 10.3923/rjvs.2010.179.188

6. Machicado C, Machicado JD, Maco V, Terashima A, Marcos LA. Association of Fasciola hepatica infection with liver fibrosis cirrhosis and cancer: A systematic review. PLOS Neg Trop Dis. 2016;10(9):e0004962. doi: 10.1371/journal.pntd.0004962

7. Al-Mahmood SS, Farhan AM, Daoud ZS, Hamed OS. Pathological study of liver lesions in cattle slaughtered at Kirkuk province abattoir. Iraqi J Vet Sci. 2017;31(1):7-16. doi: 10.33899/ijvs.2017.126713

8. Carcella S, Hanna S, Brennan G, Solana H, Fairweather I. Fasciola hepatica: Histological changes in the somatic and reproductive tissues of liver fluke following closantel treatment of experimentally-infected sheep. Vet Parasitol. 2016;215:38-47. doi: 10.1016/j.vetpar.2015.10.029

9. Suvarna SK, Layuton C, Bancroft JD. Bancroft's theory and practice of histological techniques. $7^{\text {th }}$ ed. New York: Churchill Livingstone Press; 2013. 70-214 p. doi: 10.1016/b978-0-7020-4226-3.00019-6

10. Goodman ZD. Grading and staging systems for inflammation and fibrosis in chronic liver diseases. J Hepat. 2007;47(2007):598-607. doi: 10.1016/j.jhep.2007.07.006

11. Corley KNG, Oliver AK, Meyerholz DK. Principle for valid histopathologic scoring in research. Vet Pathol. 2013;50(6):1-22. doi: 10.1177/0300985813485099

12. Mendes RE, Zafra R, Perez RA, Buffoni L, Martinez A, Tendler M, PerezI J. Evaluation of local immune response to Fasciola hepatica experimental infection in the liver and hepatic lymph nodes of goats immunized with Sm14 vaccine antigen. J Comp Pathol. 2009;141(4):298-305. doi: 10.1016/j.jcpa.2009.08.083

13. Kadir MA, Ali NH, Ridha RGM. Prevalence of helminths pneumonia and hepatitis in Kirkuk slaughterhouse Kirkuk Iraq. Iraqi J Vet Sci. 2012;26(III):83-88. doi: 10.33899/ijvs.2008.5722

14. Kadir MA, Rasheed SA. Prevalence of some parasitic helminths among slaughtered ruminants in Kirkuk Iraq. Iraqi $\mathrm{J}$ Vet Sci. 2008;22(2):81-85. doi: 10.33899/ijvs.2008.5722

15. Islam KM, Islam MD, Rauf SMA, Khan A, Hossain MK, Sarkar S, Rahman M. Effects of climatic factors on prevalence of developmental stages of Fasciola gigantica infection in Lymnaea snails (Lymnaea auricularia var rufescens) in Bangladesh. Arch Razi Inst. 2014;70(3):87-194. doi: 10.7508/ari.2015.03.007

16. Novobilsky A, Novak J, Bjorkman C, Hoglund J. Impact of meteorological and environmental factors on the spatial distribution of Fasciola hepatica in beef cattle herds in Sweden. Vety Res. 2015;11:128. doi: 10.1186/s12917-015-0447-0 
17. Mendes EA, Mendes TO, Santos SL, Souza DM, Bartholomeu DC, Martins IV, Silva LM, Lima WS. Expression of IL-4 IL-10 and IFN- $\gamma$ in the liver tissue of cattle that are naturally infected with Fasciola hepatica. Vet Parasitol. 2013;195:177-182. doi: 10.1016/j.vetpar.2013.03.035

18. Elshraway NT, Mahmoud WG. Prevalence of fascioliasis (liver flukes) infection in cattle and buffaloes slaughtered at the municipal abattoir of El-Kharga Egypt. Vet World. 2017;10(8):914-917. doi: 10.14202/vetworld.2017.914-917

19. McGavin MD, Zachary JF. Pathological basis of veterinary disease. $6^{\text {th }}$ ed. New York: Mosby Elsevier; 2017. doi: 10.1016/b978-0-32335775-3.00026-6

20. Zhang F, Guo A, Hou J, Sun M, Sheng Z, Zhang X, Huang W, Elsheikha H, Zhu X. Serum levels of cytokines in water buffaloes experimentally infected with Fasciola gigantica. Vet Parasitol. 2017;7(28):1-23. doi: 10.1016/j.vetpar.2017.07.028

21. Shi M, Wei1 Z, Elsheikha H, Zhang F, Sheng Z, Lu1 K, Wang D, Huang W, Zhu X. Dynamic expression of cytokine and transcription factor genes during experimental Fasciola gigantica infection in buffaloes. Parasit Vect. 2017;10(602):1-12. doi: 10.1186/s13071-0172538-1
22. Tlibaa O, Moirea N, Vernb Y, Boularda C, Chauvinc A, Sibillea P. Early hepatic immune response in rats infected with Fasciola hepatica. Vet Res. 2002;33(2002):261-270. doi: 10.1051/vetres:2002014

23. Aghbali A, Rafieyan S, Khosroshahi L, Baradaran B, Shanehbandi D, Kouhsoltani M. IL-4 induces the formation of multinucleated giant cells and expression of $\beta 5$ integrin in central giant cell lesion. Med Oral Pathol: Oral Cir Bucal. 2017;22(1):1-6. doi: 10.4317/medoral.20935

24. Shao DD, Suresh R, Vakil V, Gomer RH, Pilling D. Pivotal Advance: Th-1 cytokines inhibit and Th-2 cytokines promote fibrocyte differentiation. J Leuk Biol. 2008;83(6):1323-1333. doi: 10.1189/jlb.1107782

25. Keeley EC, Mehrad B, Strieter RM. Fibrocytes: Bringing New insights into mechanisms of inflammation and fibrosis. Inter $\mathbf{J}$ Biochem Cell Biol. 2009;42(4):535-542. doi: 10.1016/j.biocel.2009.10.014

26. Ishikawa T, Meier SV, Heitman SJ. Biliary obstruction caused by the liver fluke Fasciola hepatica. Can Med Assoc J. 2016;188(7):524526. doi: 10.1503/cmaj.150696 